\title{
The Possibility of an Evolutionary Semantics
}

\author{
Maxine Sheets-Johnstone \\ University of Oregon
}

Editors' Note: The following discussion of human and nonhuman "language" by Professors Sheets-Johnstone and Bishop was presented at the Pacific Division meetings of the Society for the Study of Ethics and Animals, held in San Francisco, California, March, 1991.

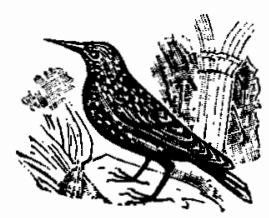

The possibility of an evolutionary semantics rests on at least three interrelated shifts in typical philosophical practice and belief: a de-privileging of human language; a recognition of iconic spatio-kinetic corporeal representation as a fundamental form of meaning in the animate world; a recognition of modes of symbolization in everyday life that are pre-reflective. Typical philosophical belief and practice are exemplified by Jonathan Bennett in his book, Rationality, ${ }^{1}$ wherein human language is taken as the standard by which the intelligence of bees is measured; by Daniel Dennett in his intentional systems theory approach to nonhuman animal behavior which, through its exclusive focus on cognitive competence in the form of beliefs, desires, and so on, overlooks corporeal intentionality and in so doing overlooks the built-in semanticity of being a body; ${ }^{2}$ by Donald Davidson in his claim that short of language, creatures cannot have beliefs, desires, and other similar kinds of psychological capacities. $^{3}$ This paper will present compelling, if necessarily abbreviated, evidence for revising typical philosophical views and adopting an evolutionary semantics perspective.

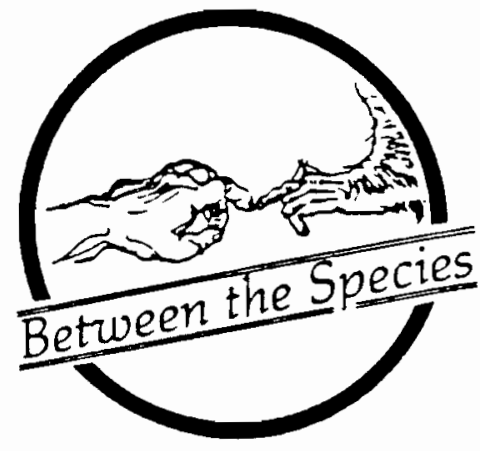

I

In diverse analyses of primary human symbolization-Freud in the psychology of dreams, ${ }^{4}$ Langer in the aesthetics of art objects, ${ }^{5}$ Leroi-Gourhan in the archaeology of prehistoric artifacts, ${ }^{6}$ Foster in the linguistics of primordial language ${ }^{7}$-great emphasis is placed both on the semanticity and on the iconicity of the symbolizing behavior. The conjoined emphasis, together with the strongly corporeal character of these symbolizing behaviors, suggests that semanticity and iconicity are intimately linked and mutually reinforcing; and further, that they are, and have been from the beginning, fundamental rather than adjunctive, or indeed, missing features of hominid communication. To show convincingly that this is so requires a critical examination of how a privileging of human language is an ahistoricizing of human language that effectively blots out the fundamentally corporeal nature of communication in the animate world, and in turn overlooks the biological pervasiveness of corporeal representation and the two basic features which define it.

Many recent theories of animal communicationDawkins' and Kreb's ${ }^{8}$ being the most extreme example-interpret communicative behavior in terms of self interest, manipulation, and the like, rather than in terms of signification or meaning. The same pragmatic concern generates the not uncommon

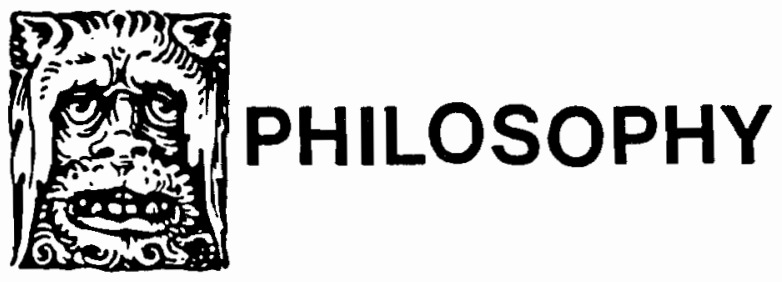


adaptationist explanation of why a verbal language arose: "It leaves much of the body free for other activities that can be carried on at the same time." Cast in such a perspective, concrete bodily acts productive at once of both sound and meaning remain unexamined. But pragmatic favoring also feeds into a privileging of human language through a depreciation of iconicitya feature putatively characteristic of nonhuman communication systems only. The two-step reasoning upholding the depreciation may be summarized as follows: 1)"The most instructive way to view the communication systems of animals is to compare these systems first with human language" 10 ;2) the linguistic elements of human language are arbitrary, not iconic, and the verbal system itself is characterized by duality of patterning. ${ }^{11}$ ("Duality of patterning" means that elementary sound units, meaningless in themselves, are combined in particular ways, making meaningful units in each particular language.) E. O. Wilson, from whose work I quoted to summarize the first reason, speaks for the majority when he unequivocally sets human language as the standard against which all nonhuman animal communication systems are to be measured and evaluated. With respect to the second reason, the notion of arbitrary over iconic elements can be traced back to Saussure. In recent times, however, it has been overwhelmingly strengthened by linguist Charles Hockett's well-known and widely accepted model of "communication systems," a model which sets forth "the design features" of language. ${ }^{2}$ Brief examination of this model will show that evolutionary estimations of nonhuman animal communication based on the privileging of human language - and note that the estimations necessarily include the communication of nonverbal and inchoately verbal ancestral hominidsare actually based on an ahistorical model: human language - whenever it is deemed to have arisen-arose full-blown from the mouths of hominids like the goddess Athena arose full-blown from the head of Zeus.

An Athena-like paradigm prevails first of all because those design features of human language identified by Hockett which are found below the human stage, that is, in the communication systems of nonhuman animals as well, do not have any status as speech (pro forma designations "pre-speech," "Proto-speech," "Prelanguage," and the like, to the contrary). Otherwise stated, it is only the final confluence of all of the design features under one cortical roof that constitutes speech and thus differ- entiates language from mere earlier hominid and other animal sounds. ${ }^{13}$ Correlatively, it is because the beginning of language is fixed at the start by definition that the paradigm prevails. Only humans have language; therefore language arose (and can only have arisen) "with their kind." Such exclusive privileging explains. why no data can be adduced which convincingly show how linguistic behavior arose from nonlinguistic behavior, for example, how the design feature discreteness - "the elementary signaling units of a language [in contrast] with the use of sound effect"14 is functionally or causally connected to what Hockett identifies as its "related characteristic," namely, "bipedal locomotion, not upright." I5 In contrast, physioanatomical changes-for example, changes in the larynx and tongue (the tongue, it should be noted, is not even mentioned in Hockett's model), or modifications in the degree of basicranial flexion-identified by other evolutionary researchers as essential to the production of speech, approximate at least to necessary conditions for the passage from nonspeech to speech and thereby possess the explanatory power credited to them. ${ }^{16}$ The behavioral motivations proposed by Hockett for the various design features-e.g., "bipedal locomotion, not upright"-lack equivalent explanatory power .

This is in fact linguist Edwin Pulleyblank's criticism with respect to the all-important design feature, duality of patterning. Precisely how could it have originated? It is purportedly based on the arbitrariness of linguistic symbols, yet a plausible explanation of how arbitrary symbols could possibly have been coined in the first place, that is, how the concept of "meaningless message elements" arose and anchored duality of patterning, is not given by Hockett. ${ }^{17}$ Indeed, Pulleyblank is rightfully skeptical of Hockett's "brilliantly successful mutation" (Hockett's phrase ${ }^{18}$ ) to explain how duality of patterning arose. He has pointed out that what is wanted are not speculative scenarios of the beginnings of verbal language but a logical sequence of "what may actually have happened." 19 He finds this logical sequence by hypothesizing and demonstrating precisely iconic rather than arbitrary initial verbal sounds.

The Athena-like paradigm effectively masks further deficiencies with respect to an evolutionary schema of hominid communication. The study of root linguistic forms is neglected, ${ }^{20}$ (they are discussed briefly below) and no rigorously detailed analysis is offered showing what "language" would actually have been like with progressively fewer than all of its design features. A 
step-by-step temporally-reversed model of the origin and evolution of language by a process of feature elimination is not given. While theoretically an account could be given, it would likely run into the kind of problematic reasonableness identified by Pulleyblank with respect to duality of patterning. The end result is that what was and what was not possible to communicate verbally at designated stages of linguistic sophistication are nowhere spelled out. In broader terms, evolutionary-semantic relationships among different forms of hominid communication--displays, gestures, vocalizations, rudimentary verbalizations, and finally speech-are nowhere conceived much less tentatively hypothesized. A bona fide evolutionary schema of hominid communication is clearly sacrificed to the privileging of human language.

\section{II}

Iconic spatio-kinetic corporeal representation is an evolutionarily identifiable biological matrix running all the way from mimicry through display behavior through gestural languages through human primordial language. In what follows, I will omit a discussion of mimicry and begin with display behavior, specifically early hominid sexual signaling behavior. [I must raise an indelicate subject in philosophical circles and will attempt to do so as painlessly as possible. You know how, if you wish to remove a band-aid in the least painful way, you do it in one fell swoop-well, I am going to talk about penile display.]

An inverse morphological/visual relationship obtains between quadrupedal and bipedal primates with respect to genitalia. Typical primate sexual signaling behavior centers on the vulva. With the advent of consistent bipedality, a shift necessarily occurred in typical primate sexual signaling behavior. Oddly enough, this shift is nowhere conceived or acknowledged by paleoanthropologists. There is insufficient time here to suggest reasons for this egregious oversight, save in the present context to say that it is almost as if with consistent bipedality, hominids are thought magically to have risen above display behavior. Neither is there time to spell out the compellingly logical grounds for assuming that penile display replaced pudendal presenting. (These grounds are spelled out in my book, The Roots of Thinking. $)^{21}$ The significance of the shift in the present context is threefold. First, there is an iconic spatio-kinetic relationship between erect posture and erect penis, erect posture being dynamically congruent with, and reinforcing, penile display with respect to upward movement, increase in apparent size, altered and more visibly distinctive shape, and degree of tautness. Second, in view of the iconic spatio-kinetic relationship, an early hominid male could semantically reinforce his display of sexual readiness and potency by assuming an erect posture. Third, fundamental species-specific meanings, such as those of sexual readiness and potency, are mediated through just such instances of corporeal representation, which is to say both that where shared meanings are represented, they are represented by symbolizing the spatio-kinetic dynamics of experience, and that semanticity is a built-in of being a body. For example, the same kind of iconic spatio-kinetic corporeal representation and the same kind of an inherent corporeal semantics are evident in the display behavior of female howler monkeys in estrus: "When approaching a male, [the female] will form an oval opening with her lips and her protruding tongue will rapidly oscillate in and out and up and down. It is clear to an observer ... that the function of this gesture is to invite copulation.... In a real sense the act is symbolic of sexual desire and readiness for copulation in the female and it stimulates appropriate responses in the male." 22 This descriptive report was written by world-renowned primatologist C. R. Carpenter. The description implicitly affirms the tongue to be a readily available spatio-kinetic analogue of the penis and the mouth a readily available spatio-kinetic analogue of the vagina in the sexual communication of howler females. Tongue and mouth are in fact sexual analogues in the behavior of other primates as well. ${ }^{23}$

Such symbolic behaviors of nonhumans and humans alike demonstrate the basically iconic rather than arbitrary nature of fundamental species behaviors. ${ }^{24}$ In general, animate bodies represent by symbolizing the spatiokinetic dynamics of their own experiences (or spatiokinetic reflexive corollaries thereof). In this respect, the Tanzsprache ("dance speech") of the honeybees is no different from hominid primordial language, and both the Tanzsprache and primordial language are no different from the tongue-flicking sexual display of female howler monkeys or from the bipedal sexual display of male early hominids. In each case, tactile-kinesthetic experience and its spatio-relational correlates are iconically linked. A brief examination of the Tanzsprache is especially edifying in demonstrating these relationships both because its status as a symbolic 
communicative system was contested and the subject of investigation for many years, ${ }^{25}$ and because in the long contentious debate, a basic corporeal dimension shared not only by human language but by the above-discussed sexual displays was overlooked.

What was not explicitly recognized is the fact that information gathered and conveyed by a dancing bee is rooted in tactile-kinesthetic experience-or its reflexive (robotic) corollary. Whether a human-like equivalent of experience is granted to the bee or not is beside the point. There is a metacorporeal similarity, a body/world iconicity, between the actual flight of the bee and the dance by which she represents her flight. This is true not only with respect to her bodily orientation to the sun in her actual flight and her correlative orientation to gravity in her symbolic rendition of the flight, for example, but with respect to other behaviors which strikingly point up the role of tactile-kinesthetic elements even further. For example, if the honeybee's flight is experimentally made more arduous, the Tanzsprache reflects the greater effort ${ }^{26}$; if the sugar concentration is high-basically a tactile datum - the vigorousness of the dance is greater. ${ }^{27}$ An iconic relationship clearly exists between tactile-kinesthetically experienced-or "recorded"-meanings and tactilekinesthetically represented meanings. The spatio-kinetic dynamics of actual corporeal activity serve as a semantic template for the spatio-kinetic representations which constitute the dance.

Primordial language is similarly rooted in tactile-kinesthetic experience. Reconstructions of root forms have demonstrated that articulatory (tactilekinesthetic) gestures are iconic with respect to their referents. For example, all root forms with ${ }^{*} \mathrm{~m}$ refer to some kind of bilateral relationship- "the fingers or hands in taking or grasping," for instance, or "two opposed surfaces in tapering, pressing together, holding together, crushing, or resting against." 28 The relationship is in each case isomorphic with the bilateral articulatory gesture which produces the sound $m$. Moreover as the examples suggest, meanings in primordial language tend to focus on "motionalrelational complexes" ${ }^{\prime 29}$ rather than discrete objects, in the same way that the Tanzsprache represents not an objectified geographical location, but how far and in what direction a sugar source is in relation to "home." Furthermore, representation in primordial language as well as in the Tanzsprache is metacorporeal. The iconic articulatory gestures are in each case a spatio-tactile/ kinetic transcription of worldly experience or activity. They specify something out in the world apart from the body yet iconically related to corporeal experience or activity. This is of course immediately apparent in the case of the Tanzsprache. But it is also clear in the case of primordial language. The bilateral relationships resting against, pressing together, or crushing, for example, are primordial perceptual meanings anchored in what might aptly be termed primordial bodily experiences, that is, in correlative "root" behaviors: resting against nest materials in sleeping, for example, or the earth in standing; pressing together in copulating or in producing the sound $m$; crushing in chewing food or pounding one thing with another.

Where the Tanzsprache and primordial language differ is in both mode of articulation and mode of communication. In the Tanzsprache articulation is of the whole body. Mode of communication is likewise a "whole body gestural system:" 30 information is transmitted tactile-kinetically from dancer to potential recruit. In primordial language, as in present-day human speech, articulation is of the supralaryngeal parts of the body [tongue, lips, larynx, and so on], ${ }^{31}$ and communication takes place not through intimate body-to-body contact of articulatory parts, but aurally, i.e., through a second sensory medium. Communication in the one instance is thus directly by way of the tactile-kinetic gestures themselves; in the other by way of the sounds the gestures create. Thus articulatory gestures constitute the language in the Tanzsprache; in primordial language, articulatory gestures are the means whereby the language is constituted. What is both interesting and significant in this regard, however, is that studies of human speech perception show speech perception to be actually speech apperception. The listener makes co-present with actual perception something that is not actually given in the perception: "the listener responds as though he is interpreting the acoustic signal in terms of the articulatory gestures that a speaker would employ to generate the word." 32 This tactile-kinesthetic decoding of speech $h^{33}$ is not random or accidental: "The human brain decodes ... the acoustic signal in terms of the articulatory maneuvers that were put together to generate the syllable.... The process of human speech inherently requires 'knowledge' of the acoustic consequences of the possible range of human supralaryngeal vocal tract speech articulation" (italics added) ${ }^{34}$ There is no reason not to assume that in primordial speech tactile-kinesthetic empathy with the 
articulatory gestures of the speaker was similarly inherently required. From this perspective the ultimate difference in mode of sensory communication between the Tanzsprache and primordial/present-day human language is the difference between actual tactile-kinetic experience (or "recording") of dance by recruit and tactile-kinesthetic empathy of listener with speaker. ${ }^{35}$

The sexual displays of a female howler monkey and of a male early hominid stand in the same relation to the tactile-kinesthetic body as primordial and presentday human language stand to the articulatory gestures of speech, and as the Tanzsprache stands to the articulatory gestures of the dancer. In each case the body is iconically representing its own experiences and is thereby communicating either its bodily dispositions of the moment, or information about something in the world. The fact that such experiences are communicated attests to species-specific tactile-kinesthetic invariants. Indeed, Hockett's design feature, interchangeability ("a speaker of a language can reproduce any linguistic message he can understand" ${ }^{36}$ ), is dependent upon just such invariants, a fact implicitly apparent in the research on speech (ap)perception cited above. Short of tactile-kinesthetic invariants, neither primordial language, present-day human language, the Tanzsprache, nor sexual displays would be possible, not in the sense that the performing individual could not continue speaking, dancing, or displaying, but that the action would be meaningless to the individual to whom it was addressed. What is represented visually, auditorily, or tactile-kinetically is in each case related to the addressed animal's own body of prior tactile-kinesthetic experiences (or activities). This is precisely the concept primatologist Stuart Altmann tries to capture by his term comsign. ${ }^{37}$ The term refers to one of the two prime factors making primate interchangeability possible; viz., most primate signals are part of the repertoire of all of the members of the species (and/or of a particular group in question), at the very least for some period of time in the animals' lives. What is true of primates is in this instance also true of bees. Potential recruits are potential dancers because tactile-kinesthetic invariants anchor interchangeability.

There is insufficient time to do more than suggest that fundamental meanings about oneself and about the world have in present-day human speech been incorporated into language itself as corporeal metaphor. In other words, though original iconic corporeal relationships are no longer apparent, corporeal representation remains a substantive part of language in the form of metaphor-the brow of a hill, for example, or counting on someone. Strong support for this suggestion comes from Lakoff's and Johnson' $\mathrm{s}^{38}$ work which has demonstrated quite clearly the bodily origin of orientational and physical metaphors, and from my own work that complements their thesis in substantiating the body as a semantic template in the origin and evolution of fundamental human practices and beliefs. ${ }^{39}$

\section{III}

Whether a matter of primates, apians, or other forms of animate life, such symbolizing modes as described above should not be conceived as thoughtfully worked out patterns of behavior. What Freud said of the dreamer-that knowledge of the symbolism as such is unconscious - is also true of the symbolizing animal, though to be unaware of the symbolism as such does not mean that the symbolizing animal is unaware of its behavior. ${ }^{40}$ Piaget's description of the buccal behavior of an infant is an apt-even strikingly pictorialconfirmation of pre-reflective symbolization. ${ }^{41}$ The infant's progressive opening and closing of its mouth coincident with its focal attempt to open a matchbox is a pre-reflective gesture symbolic of the dynamics and anticipated result of its manual activity. The oral gesture is a spontaneous tactile-kinesthetic symbol, a spatiokinetic analogue of the behavior: opening a matchbox. The infant is unaware of the symbolism as such, but clearly knows corporeally, i.e., in a tactile-kinesthetic sense, the meanings: open and opening. The inherent epistemological requirements of speech perception discussed above-the listener must know corporeally the articulatory gestures of the speaker-is again corroborative of the same fact. In equal terms, the sexual display embodied by the protruding and moving tongue of a female howler monkey or by the erect posture of a sexually aroused and motivated male early hominid is not the result of thought exercises in corporeal representation or in the semantics and iconicity of symbols; it is a spontaneous (species-specific) symbolic behavior rooted in pre-reflective tactile-kinesthetic corporeal experience.

The evidence presented here shows that the possibility of an evolutionary semantics is not akin to the possibility of putting a human on Mars, or to the 
possibility of mapping all possible neurological happenings in brains. The possibility of an evolutionary semantics is within immediate grasp, once we climb down from our pedestals, once we begin fathoming the bodies we are, once we begin taking evolution seriously.

\section{Notes}

\section{${ }^{1}$ Jonathan Bennett, Rationality (London: Routledge \&} Kegan Paul, 1971).

${ }^{2}$ Daniel C. Dennett, "Intentional Systems in Cognitive Ethology: The 'Panglossian Paradigm' Defended," Behavioral and Brain Sciences 6 (1983): 343-390.

3 Donald Davidson, "Thought and Talk," in Truth \& Interpretation (Oxford: Clarendon Press, 1985), pp. 155-170.

${ }^{4}$ Sigmund Freud, Complete Psychological Works of Sigmund Freud, Vols. IV, V (London: Hogarth Press, 1953).

${ }^{5}$ Susanne Langer, Philosophy in a New Key (New York: New American Library, 1948); Feeling and Form (New York: Charles Scribner's Sons, 1953.).

${ }^{6}$ Andre Leroi-Gourhan, Prehistoire de l'art occidental (Paris: Mazenod, 1971).

${ }^{7}$ Mary LeCron Foster, "The Symbolic Structure of Primordial Language," in Human Evolution: Biosocial Perspectives, ed. Sherwood L. Washburn and Elizabeth R. McCown (Menlo Park, Calif.: Benjamin/Cummings, 1978), pp. 77-121; "Reconstruction of the Evolution of Language," in Handbook of Symbolic Evolution, ed. A. Lock and C. Peter, forthcoming from Oxford University Press.

${ }^{8}$ R. Dawkins and J. R. Krebs, "Animal Signals: Information or Manipulation?," in Behavioural Ecology, eds. J. R. Krebs and N. B. Davies (London: Basil Blackwell, 1978), pp. 282-309.

${ }^{9}$ C. F. Hockett, "The Origin of Speech," Scientific American 203 (1960): 90.

${ }^{10}$ E. O. Wilson, "Animal Communication," Scientific American 227/3 (1972): 52-60.

${ }^{11}$ See, for example, F. de Saussure, Course in General Linguistics (New York: Philosophical Library, 1959); C. F. Hockett, "Origin of Speech," and "Logical Considerations in the Study of Animal Communication," in Animal Sounds and Communication, eds. W. E. Lanyon and W. N. Tavolga (Washington D. C.: American Institute of Biological Science, 1960); C. F. Hockett and R. Ascher, "The Human Revolution," Current Anthropology 5 (1964): 135-147; C. F.
Hockett and S. A. Altmann, "A Note on Design Features," in Animal Communication, (Bloomington: Indiana University, 1969), pp. 61-72; H. D. Steklis and S. R. Harnad, "From Hand to Mouth: Some Critical Stages in the Evolution of Language," Annals of the New York Academy of Sciences 280 (1976): 445-455; H. S. Terrace and T. G. Bever, "What Might Be Learned From Studying Language in the Chimpanzee? The Importance of Symbolizing Oneself," Annals of the New York Academy of Sciences 280 (1976): 579-588; R. L. Holloway, "Culture: A Human Domain," Current Anthmpology 10 (1969): 395-412; E. Von Glaserfield, "The Development of Language as Purposive Behavior, Annals of the New York Academy of Sciences 280 (1976): 212-226; N. Tanner and A. Zhilman, "Discussion Paper: The Evolution of Human Communication: What Can Primates Tell Us?, Annals of the New York Academy of Sciences 280 (1976): 467-480; S. L. Washburn and S. C. Strum, "Concluding Comments," in Perspectives on Human Evolution 2, eds. S. L. Washburn and P. Dolhinow (New York: Holt, Rinehart and Winston, 1972), pp. 469-491.

${ }^{12}$ See C. F. Hockett references in Note 11.

${ }^{13}$ For example, Hockett has stated both that "No known system of nonhuman animal communication has duality of patterning" and that "The crucial feature shared by all languages in the ethnographic present, but which we assume was missing from prelanguage, is duality of patterning." See C. F. Hockett, Man's Place in Nature (New York: McGraw-Hill, 1973), pp. 106 and 414 respectively.

${ }^{14}$ Hockett, "The Origin of Speech," p. 90.

${ }^{15}$ Ibid., p. 93.

${ }^{16}$ See Philip Lieberman, "On the Nature and Evolution of the Biological Bases of Language," in Glossogenetics, ed. E. de Grolier (New York: Harwood, 1983), pp. 91-114, "Primate Vocalizations and Human Linguistic Ability," in Perspectives on Human Evolution 2, ed. Sherwood L. Washburn and Phyllis J. Dolhinow (New York: Holt, Rinehart, and Winston, 1972). pp. 444-68; J.T. Laitman, "The Evolution of the Hominid Upper Respiratory System and Implications for the Origin of Speech," in Glossogenetics, ed. E. de Grolier (New York: Harwood, 1983), pp. 63-90.

${ }^{17}$ Anthropologist Gordon Hewes has remarked that "The greatest obstacle in any glottogonic theory is not that vocal sounds, or manual gestures, or whatever, could not be used as linguistic signs, but how any system based on seemingly arbitrary signs would have got started." See his "The Current Status of the Gestural Theory of Language Origin," in Annals of the New York Academy of Sciences 280 (1976): 482-504.

${ }^{18}$ Hockett and Ascher, "The Human Revolution," p. 144. 
${ }^{19}$ Edwin G. Pulleyblank, "The Beginnings of Duality of Patterning in Language," in Glossogenetics, ed. E. de Grolier (New York: Harwood, 1983), p. 373.

${ }^{20}$ For an analysis of these forms, see Foster, "The Symbolic Structure of Primordial Language," and "Reconstruction of the Evolution of Language"; See also Morris Swadesh, The Origin and Diversification of Language (Chicago: Aldine-Atherton, 1971); and Pulleyblank, "Beginnings of Duality of Patterning."

${ }^{21}$ Philadelphia: Temple University Press, 1990.

${ }^{22}$ C. R. Carpenter, "Societies of Monkeys and Apes," in Primate Social Behavior, ed. C. H. Southwick (New York: Van Nostrand Reinhold, 1963), pp. 49-50.

${ }^{23}$ See The Roots of Thinking, p. 114 for examples.

24 There are, of course, exceptions to this basic iconicity. The eye spot flash of a threatening/warning baboon is akin to the wagging finger of a threatening/warning mother. In traditional semantic terms, similarity between signified and signifier appears non-existent in these instances.

${ }^{25}$ For a general review see J. L. Gould, "The DanceLanguage Controversy," Quarterly Review of Biology 51/2 (1976): 211-244. See also Donald R. Griffin, The Question of Animal Awareness (New York: Rockefeller University Press, 1976), "Prospects for a Cognitive Ethology," Behavioral and Brain Sciences 1/4 (1978): 527-538, and Animal Thinking (Cambridge: Harvard University Press, 1984).

26 Gould, "Dance-Language Controversy"; Karl von Frisch, Bees (Ithaca: Cornell University Press, 1950), and The Dance Language and Orientation of Bees (Cambridge: Harvard University Press, 1967).

27 Gould, "Dance-Language Controversy"; von Frisch, Bees and The Dance Language.

${ }^{28}$ Foster, "Symbolic Structure," p. 110.

${ }^{29}$ Mary LeCron Foster, "The Growth of Symbolism in Culture," in Symbol as Sense, ed. M. LeCron Foster and S. Brandes (New York: Academic Press, 1980), pp. 371-397.

${ }^{30}$ The phrase is linguist Philip Lieberman's and is one he uses to describe the findings of primatologist Emil Menzel regarding communication in chimpanzee societies. See Philip Lieberman, "On the Nature and Evolution of the Biological Bases of Language."

${ }^{31}$ In addition to Foster's "Symbolic Structure," see Philip Lieberman, "Primate Vocalizations and Human Linguistic
Ability," and "On the Nature and Evolution of the Biological Bases of Language"; J. T. Laitman, "The Evolution of the Hominid Upper Respiratory System."

${ }^{32}$ Philip Lieberman, "On the Evolution of Language: A Unified View," in Primate Functional Morphology and Evolution, ed. R. H. Tuttle (The Hague: Mouton, 1975), p. 535.

${ }^{33}$ See A. M. Liberman, F. S. Cooper, P. Shankweiler, and M. Studdert-Kennedy, "Perception of the Speech Code," Psychological Review 74 (1967): 431-461, and "The Motor Theory of Speech Perception Revised," Cognition 21 (1985): 1-36.

${ }^{34}$ Lieberman, “On the Evolution of Language," p. 504.

${ }^{35}$ It should be noted that Alvin Liberman, in his motor theory of speech perception, does not speak of empathy but brain modules to explain the listener's knowledge of the speaker's articulatory gestures, an explanatory model in keeping with models in cognitive science, but not on that account above either elaboration or explanatory criticism.

${ }^{36}$ Hockett, "The Origin of Speech," p. 90.

${ }^{37}$ Stuart A. Altmann, "The Structure of Primate Social Communication," in Social Communication Among Primates, ed. S. A. Altmann (Chicago: University of Chicago Press, 1967), pp. 325-362.

${ }^{38}$ Metaphors We Live By (Chicago: Chicago University Press, 1980). See also "Conceptual Metaphor in Everyday Language," Journal of Philosophy 78/8 (August 1980): 453-486.

\section{${ }^{39}$ The Roots of Thinking.}

${ }^{40}$ Ethologists and sociobiologists have both documented this awareness, as has Charles Darwin. See, for example, Peter Marler, "On the Origin of Speech from Animal Sounds," in The Role of Speech in Language, ed. J. F. Kavanagh and J. E. Cutting (Cambridge: MIT Press, 1975), pp. 11-37, and "An Ethological Theory of the Origin of Vocal Learning," in Origins and Evolution of Language and Speech, ed. Stevan R. Harnad, Horst D. Steklis, and Jane B. Lancaster, Annals of the New York Academy of Sciences 280 (1976): 386-395; Richard Dawkins and J. R. Krebs, "Animal Signals: Information or Manipulation?"; Charles Darwin, The Descent of Man and Selection in Relation to Sex (Princeton: Princeton University Press, 1981 [1871]), p. 258.

41 Jean Piaget, La naissance de l'intelligence chez l'enfant, $6^{\mathrm{e}} \mathrm{me}$ ed. (Neuchatel: Delachaux et Niestle, 1968), pp. 293-294. 